\title{
Timpanismo espumoso em bovinos leiteiros em pastagens de Trifolium spp. (Leg.Caesalpinoideae) ${ }^{1}$
}

\author{
André Gustavo Cabrera Dalto², Paulo Mota Bandarra², Pedro Miguel \\ Ocampos Pedroso², Fábio de Souza Guagnini², Juliano de Souza Leal², \\ Djeison Lutier Raymundo² e David Driemeier ${ }^{2 *}$
}

\begin{abstract}
Dalto A.G.C., Bandarra P.M., Pedroso P.M.O., Guagnini F.S., Leal J.S., Raymundo D.L., Driemeier D. 2009. [Leguminous bloat in dairy cattle on Trifolium spp. pastures.] Timpanismo espumoso em bovinos leiteiros em pastagens de Trifolium sp. (Leg.Caesalpinoideae). Pesquisa Veterinária Brasileira 29(5):401-403. Setor de Patologia Veterinária, Universidade Federal do Rio Grande do Sul, Av. Bento Gonçalves 9090, Agronomia, Porto Alegre, RS 91540-000, Brazil. E-mail: davetpat@ufrgs.br

Leguminous bloat may occur in cattle which graze pastures consisting of lush forages. In a dairy farm located on the municipality of São Francisco de Paula, Rio Grande do Sul, eight out of 66 cows died suddenly after being transferred to a paddock whose pastures were composed of Trifolium repens and Trifolium pratense. Animals were found dead in the morning of the next day after being transferred; no clinical signs were noticed. Main gross findings included enhanced abdominal volume, protrusion and congestion of the tongue and vagina, ruminal distension, pale liver, and enhanced spleen. Histologically, there were lung congestion and edema, and splenic lymphoid hyperplasia. The evidence of leguminous forages consumption associated with the pathological findings and the absence of growth on bacteriology confirmed the diagnosis.
\end{abstract}

INDEX TERMS: Bloat, Trifolium pratense, T. repens, Leguminosae Caesalpinoideae, cattle.

RESUMO.- O pastejo de plantas leguminosas que provocam fermentação excessiva pode causar surtos de timpanismo e mortes em ruminantes. Em uma propriedade no município de São Francisco de Paula, Rio Grande do Sul, oito bovinos de um total de 66 morreram subitamente, ao haverem sido transferidos de um potreiro de campo nativo, para outro cuja pastagem era composta por Trifolium repens e Trifolium pratense. Os animais foram encontrados mortos no amanhecer do dia seguinte à transferência, não foram observados sinais clínicos prévios. Os principais achados macroscópicos incluíram aumento de volume abdominal, protrusão de vagina e língua, distensão ruminal, fígado de coloração pálida e aumento do baço. Na histologia, havia congestão e edema pulmonares e hiperplasia linfóide difusa e acentuada no baço. A evidência de ingestão das

\footnotetext{
${ }^{1}$ Recebido em 6 de novembro de 2008.

Aceito para publicação em 18 de dezembro de 2008.

2 Departamento de Patologia Clínica Veterinária, Universidade Federal do Rio Grande do Sul (UFRGS), Av. Bento Gonçalves 9090, Porto Alegre, RS 91540-000, Brasil. *Autor para correspondência: davetpat@ufrgs.br
}

leguminosas associada aos achados patológicos e à ausência de microrganismos no exame bacteriológico confirmaram o diagnóstico de timpanismo.

TERMOS DE INDEXAÇÃO: Timpanismo, Trifolium pratense, $T$. repens, Leguminosae Caesalpinoideae, bovinos.

\section{INTRODUÇÃO}

Timpanismo é caracterizado por dilatação anormal do rúmen por retenção excessiva de gases de fermentação na forma de espuma persistentemente dispersa no conteúdo ruminal ou gás livre. A ocorrência de timpanismo espumoso é associada com o pastoreio de plantas que provocam fermentação excessiva ou dieta com excesso de grãos finamente triturados (Radostits et al. 2002, RietCorrea 2007). Embora controverso, o mecanismo de formação da espuma está associado com o estágio de desenvolvimento das plantas leguminosas e o tipo de proteínas citoplasmáticas solúveis presentes nas folhas dessas plantas (Majak et al. 1995). Essas substâncias seriam digeridas mais rapidamente do que o usual pela microbiota ruminal e as bolhas de gás resultantes da fer- 
mentação permaneceriam capturadas entre as partículas dispersas do conteúdo ruminal (Lowe et al. 1991).

O principal fator de risco do timpanismo agudo é o consumo de pastagens compostas por mais de $50 \%$ de leguminosas (Radostits et al. 2002, Riet-Correa 2007). A doença tem sido associada, principalmente, com a ingestão de espécies de Trifolium ( $T$. repens, $T$. pratense e T. subterraneum) e Medicago (M. sativa e M. hispida) (Riet-Correa 2007), que são pobres em fibra e têm alto teor de carboidratos solúveis e proteínas de elevada degradabilidade ruminal (Tokarnia et al. 2000, Rajan et al. 1996). A doença afeta principalmente bovinos e os bezerros de até um ano de idade são mais resistentes que os adultos (Riet-Correa 2007). Há variações na susceptibilidade associadas com características hereditárias como composição das proteínas salivares, taxa de salivação, motilidade e capacidade ruminais (Cockrem et al. 1987). Os sinais clínicos podem surgir 20 minutos após a introdução dos animais nas pastagens (Tokarnia et al. 2000) e incluem aumento do volume abdominal (inicialmente esquerdo), dispnéia, dificuldade para eructação, decúbito e morte. Na maioria dos casos, são registrados casos de "morte súbita" devido à brevidade de exposição dos sinais clínicos (Riet-Correa 2007). Os principais achados de necropsia são fígado e baço pálidos, pulmão pálido e enfisematoso, vesícula biliar repleta e rins conges-

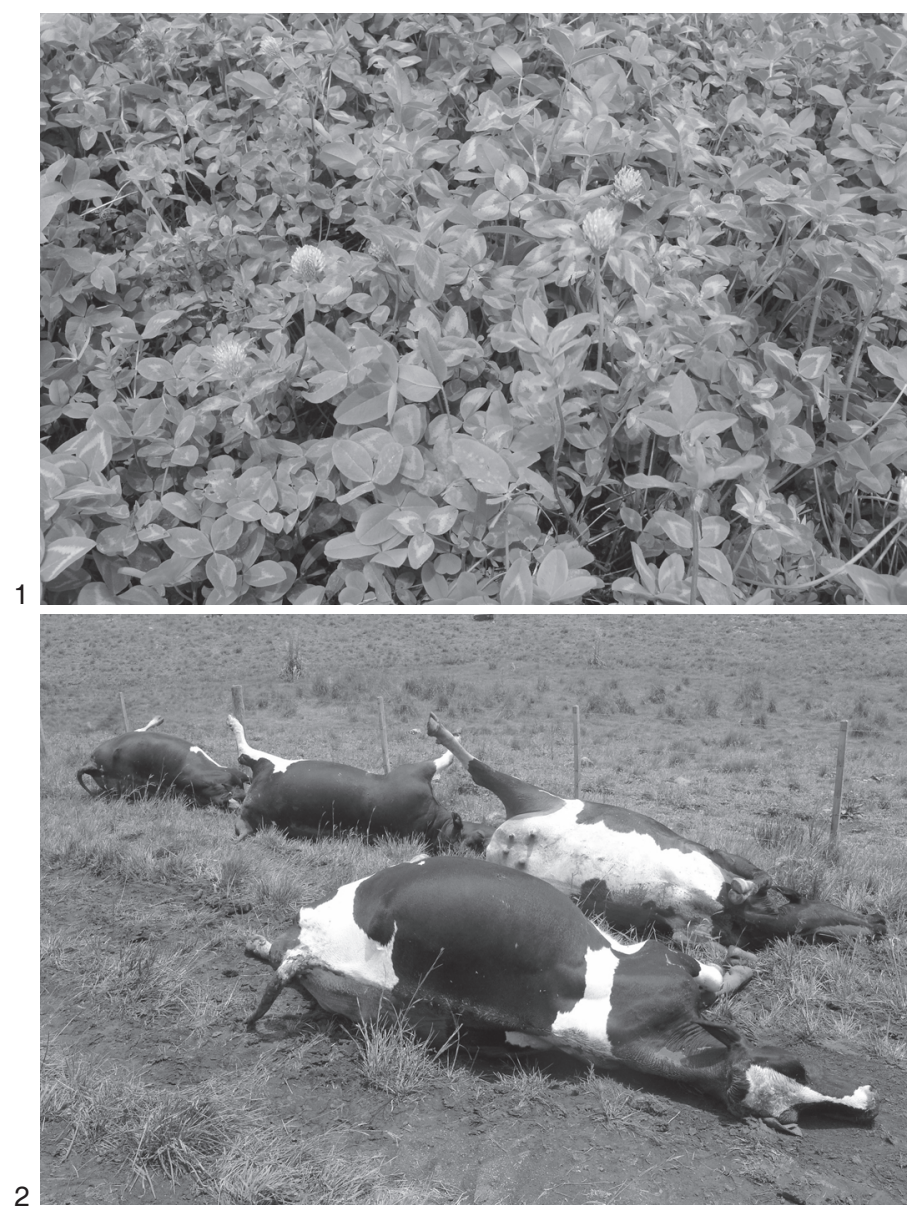

tos e de consistência amolecida (Radostits et al. 2002, Riet-Correa 2007). O tratamento depende das circunstâncias, mas os animais devem ser retirados imediatamente das pastagens onde ocorreu o problema. Nos casos graves, é necessária a ruminotomia de emergência. Para o controle, recomenda-se o emprego de pastagens consorciadas (leguminosas e gramíneas) e a administração de antiespumantes aos animais (Radostits et al. 2002, RietCorrea 2007). Este estudo relata a ocorrência de um surto de timpanismo espumoso em bovinos leiteiros, após ingestão de pastagens compostas por Trifolium repens e Trifolium pratense no Rio Grande do Sul.

\section{MATERIAL E MÉTODOS}

Em janeiro de 2006, realizaram-se necropsias em seis bovinos na zona rural do município de São Francisco de Paula, Rio Grande do Sul. Os dados epidemiológicos foram registrados pelo médico veterinário responsável pelo rebanho. Durante as necropsias, fragmentos de diversos órgãos foram coletados e fixados em formol $10 \%$, processados de forma rotineira para histologia, incluídos em parafina, cortados a $5 \mu \mathrm{m}$ de espessura e corados pela hematoxilina-eosina (HE) (Prophet et al. 1992). Adicionalmente, amostras de sangue sem anticoagulante e de baço foram encaminhadas para bacteriologia.

\section{RESULTADOS}

Sessenta e seis vacas da raça Holandesa foram transferidas de um piquete de campo nativo para uma pastagem consorciada de Trifolium repens (trevo-branco) e Trifolium pratense (trevo-vermelho) (Fig.1), ao entardecer de um dia de janeiro de 2006. Ao amanhecer do dia seguinte, oito animais foram encontrados mortos

Fig.1. Aspecto da pastagem composta por Trifolium repens (trevo-branco) e Trifolium pratense (trevo-vermelho), onde houve o surto de timpanismo espumoso em rebanho bovino.

Fig.2. Vacas holandesas mortas com acentuada distensão abdominal, no surto de timpanismo espumoso.

Fig.3. Vaca holandesa morta com edema na cabeça e protrusão da língua no surto de timpanismo espumoso.

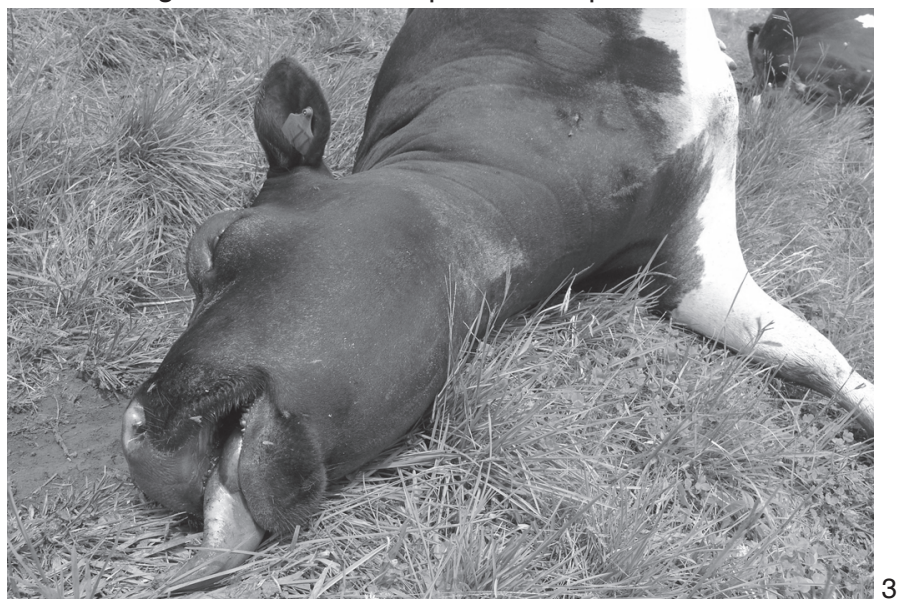


(Fig.2). Durante a necropsia, as principais alterações foram aumento de volume abdominal, protrusão de reto, vagina e edema da cabeça e língua protrusa (Fig.3), fígado com coloração pálida e baço levemente aumentado de tamanho. $O$ exame histopatológico revelou pulmão com edema difuso e congestão acentuada e baço com hiperplasia linfóide difusa acentuada. Não houve crescimento bacteriano.

\section{DISCUSSÃO}

Este diagnóstico foi fundamentado nos dados epidemiológicos, achados de necropsia e histopatologia (RietCorrea 2007). As evidências de que as plantas haviam sido consumidas pelos bovinos no piquete associada com os achados macroscópicos e histológicos e com a ausência de outras alterações significativas comprovam a ocorrência de timpanismo por ingestão de leguminosas pelos bovinos. As possibilidades de infecções bacterianas que cursam com "morte súbita" como o carbúnculo hemático, carbúnculo sintomático, edema maligno e hemoglobinúria bacilar foram excluídas com base na bacteriologia e patologia (Riet-Correa 2007). As mortes por picada de cobra e fulminação por raio foram descartadas por ausência de lesões locais características dessas doenças. É importante que a necropsia seja realizada o mais rapidamente possível após a morte dos animais, para que as alterações post-mortem não compliquem a interpretação dos achados macroscópicos (Riet-Correa 2007).
Agradecimentos.- Este estudo foi financiado, em parte, pelo Conselho Nacional de Desenvolvimento Científico e Tecnológico (CNPq) e pela Coordenação de Aperfeiçoamento de Pessoal de Nível Superior (CAPES). Os autores agradecem ao Professor Cláudio Estêvão Farias da Cruz (UFRGS) pela revisão deste artigo.

\section{REFERÊNCIAS}

Cockrem F.R.M., McIntosh J.T., McLaren R.D. \& Morris C.A. 1987. The relationship between volume of rumen contents and genetic susceptibility to pasture bloat. Anim. Prod. 45:43-47.

Lowe L.B., Ball G.J., Carruthers V.R., Dobos R.C., Lynch G.A., Moate P.J., Poole P.R. \& Valentine S.C. 1991. Monensin controlled-release intraruminal capsule for control of bloat in pastured dairy cows. Aust. Vet. J. 68(1):17-20.

Majak W., Hall J.W. \& McCaughey W.P. 1995. Pasture management strategies for reducing the risk of legume bloat in cattle. J. Anim. Sci. 73:1493-1498.

Prophet E.B., Mills B., Arrington J.B. \& Sobin L.H. 1992. Laboratory Methods in Histotechnology. Armed Forces Institute of Pathology, American Registry of Pathology, Washington, DC. 279p.

Rajan G.H., Morris C.A., Carruthers V.R., Wilkins R.J. \& Wheeler T.T. 1996. The relative abundance of a salivary protein, bSP30, is correlated with susceptibility to bloat in cattle herds selected for high or low bloat susceptibility. Anim. Gen. 27(6):407-414.

Radostits O.M., Gay C.C., Blood D.C. \& Hinchcliff K.W. 2002. Clínica Veterinária. $9^{a}$ ed. Guanabara Koogan, Rio de Janeiro. 1737p.

Riet-Correa F. 2007. Timpanismo espumoso em pastagens de leguminosas, p.326-343. In: Riet-Correa F., Schild A.L., Lemos R.A.A. \& Borges J.R.J. (Eds), Doenças de Ruminantes e Eqüinos. Vol.2. $3^{\text {a }}$ ed. Editora Pallotti, Santa Maria, RS.

Tokarnia C.H., Döbereiner J. \& Peixoto P.V. 2000. Plantas Tóxicas do Brasil. Editora Helianthus, Rio de Janeiro. 320p. 